\title{
A cinematografia no ensino de filosofia
}

\author{
Cinematography in the teaching of philosophy
}

\author{
Marcos Machado \\ Doutorando na Universidade Federal do Paraná, Curitiba, Paraná, Brasil. \\ marcos.machado@ufabc.edu.br - https://orcid.org/0000-0001-9831-3360
}

Recebido em 31 de outubro de 2019

Aprovado em 19 de março de 2020

Publicado em 30 de julho de 2020

RESUMO: O propósito desse artigo é sugerir algumas pistas para explorar, no âmbito do ensino de filosofia, a dimensão de longas-metragens, sobretudo os que expõem conteúdo de caráter filosófico. Além disso, esperamos evitar algumas práticas que limitam a sua potencialidade, principalmente quando apenas são transpostos de modo didático as ideias, as situações ou os conceitos presentes em determinado filme como artifício atenuador da complexa relação ensino-aprendizagem ou, ainda, quando a obra cinematográfica é utilizada como um dispositivo que busca tão somente sensibilizar os estudantes para o assunto abordado em certo texto filosófico. Trata-se, então, de seguir os passos de alguns filósofos que analisaram a arte de reproduzir imagem em movimento e que insinuaram que determinada linguagem e estética cinematográfica possui aspecto filosófico, a saber: Theodor Adorno e Max Horkheimer (1985); Walter Benjamin (1987); Gilles Deleuze (1985); Jacques Rancière (2012); João Maria Mendes (2013); Julio Cabrera (2006).

Palavras-chave: Ensino de filosofia; Cinematografia; Metodologia; Imagem; Movimento.

ABSTRACT: The purpose of this article is to give some suggestions to explore, in the area of philosophy teaching, the dimension of feature films, especially those which expose philosophical content. In addition, we hope to avoid some practices that limit their potential, mainly when the ideas, situations or the concepts present in a given film are only didactically transposed. In this case, as an attenuating method in the complex teaching-learning relationship, or even when a cinematographic work is used as a device that only seeks to sensitize students to the addressed subject in a certain philosophical text. It is then a matter of following in the footsteps of some philosophers who analyzed the art of displaying moving images and who imply that certain language and film aesthetics have philosophical characteristics, namely: Theodor Adorno and Max Horkheimer (1985); Walter Benjamin (1987); Gilles Deleuze (1985); Jacques Rancière (2012); João Maria Mendes (2013); Julio Cabrera (2006). Keywords: Philosophy teaching; Cinematography; Methodology; Image; Movement.

\section{Introdução}

Quando o assunto é exibição de filmes no âmbito do ensino de filosofia, podemos interrogar essa complexa relação das seguintes maneiras: como evitar um uso corrente desse recurso no ambiente educacional, isto é, "um uso viciado, dominante, clichê; uma prisão" 
(FREITAS, 2013, p. 478)? Em outras palavras: em recorrer ao filme apenas para efetuar uma "transposição didática de ideias, situações ou conceitos, como imagem do pensamento, enfim, como recurso facilitador da relação ensino-aprendizagem" (Op. Cit., p. 478)? Aliás, como aproveitar o recurso cinematográfico e explorar a sua potencialidade pedagógica e filosófica no contexto do ensino mencionado? Há alguma estratégia específica para relacionar um filme com o conteúdo a ser transmitido? Pode "o cinema ser filosofia, pode um filme ser filósofo? O filme-ensaio que incluiu discurso filosófico ou se dedica a enunciações argumentativas sobre o sentido da vida e do mundo filosofa?" (MENDES, 2013, p. 10).

Diante dessas problematizações, o presente artigo busca indicar possibilidades para explorar, na esfera do ensino de filosofia, a dimensão de longas-metragens, especialmente os que expõem conteúdo de caráter filosófico, mesmo que, o ambiente de uma sala de aula, tenham sujeitos com diversos gostos estéticos.

Nesta perspectiva, a dificuldade da relação entre filosofia e cinema amplia-se, à medida que ambos fenômenos possuem às suas particularidades. Por um lado, os filósofos expressam o seu ponto de vista sobre a realidade em que estão inseridos através de um "método" específico de investigação filosófica. Por outro lado, os diretores cinematográficos, sobretudo os que produzem cinema com idiossincrasia experimental, cuja produção artística propõe-se inventar outros modos de expressão, outra linguagem e outra estética. Diferentemente, portanto, ao modo de produção cinematográfico em que sua característica expõe uma dimensão comercial, isto é, um produto que comumente espera fascinar um público de massa por meio de entretenimento e padrões fixos. Por este motivo, os cineastas de obras caracterizadas como cinema experimental exteriorizam a sua visão de mundo através de métodos - linguagem e estética - peculiares, uma vez que determinados diretores optam em narrar uma história destacando os acontecimentos de maneira linear; enquanto que outros, por sua vez, priorizam uma descrição de modo aleatório.

Em todo caso, ambas as narrativas - filosofia e cinema - tencionam romper com uma reprodução que causa os efeitos meramente de entretenimento e de padrão fixo.

Dessa forma, iniciaremos esta análise filosófica sobre a arte de narrar com imagens em movimento, a partir de alguns teóricos da reconhecida "Escola de Frankfurt", os quais investigaram a cultura de sua época, bem como os efeitos da cinematografia sobre a mesma. Além do mais, destacaremos as abordagens dos filósofos Gilles Deleuze (1985), Jacques Rancière (2012), João Maria Mendes (2013) e Julio Cabrera (2006).

\section{Breve apreciação filosófica sobre o cinema}

De acordo com Theodor Adorno e Max Horkheimer, no contexto da denominada indústria cultural, o cinema (Cf. ADORNO; HORKHEIMER, 1985, p. 114) não precisa apresentar-se como arte. O cinema, bem como o rádio "não passam de um negócio, eles a utilizam como uma ideologia destinada a legitimar o lixo que propositalmente produzem" (Op. Cit., p. 114).

Por sua vez, Walter Benjamin (1987), seguindo os rastros de Adorno e Horkheimer (1985), mas amenizando a crítica de ambos, esclareceu que a reprodutibilidade técnica do 
filme não só se acoplou a essa dinâmica como a ela necessita estar acoplada, pois "a produção de um filme é tão cara que um consumidor, que poderia, por exemplo, pagar um quadro, não pode mais pagar um filme" (Ibid., 1987, p. 172). Como resultado, essa criação e exposição em massa deprecia a unicidade da obra e suprime o seu caráter estimável, "em outras palavras, sua aura" (Ibid., p. 171). Por outro lado, o "filme serve para exercitar o homem nas novas percepções e reações exigidas por um aparelho técnico" (Ibid., p. 174). Neste contexto, o caráter artístico de um longa-metragem na óptica de Benjamin (1987), embora dependa também de todo um equipamento tecnológico, a saber, montagem e edição, necessita em igual medida da representação do ator, pois diante do produto técnico (câmera) o intérprete humaniza a relação criadora do filme. $O$ artista cinematográfico, no entanto, em certa medida não se identifica com o intérprete de teatro, uma vez que não é tão necessário que ele seja de fato um excelente ator, dado que interpretará de acordo com as orientações dos especialistas - produtor, diretor, operador, engenheiros - podendo, inclusive, refazer, caso seja necessário, a interpretação.

Grosso modo, para que dado longa-metragem consiga expressar as características do cineasta é necessário levar em consideração também a performance do ator, sendo esse um agente especializado em atuação ou não. Conforme representado, por exemplo, através de

uma estética árida e faminta pela imperfeição que se associa a atuações dissonantes entre atores profissionais e não profissionais, como em Deus e o Diabo na Terra do Sol (1963), de Glauber Rocha. (SANTOS, 2018, p. 5).

Ou, ainda, conforme exposto no filme Bacurau (2019), dos diretores brasileiros Kleber Mendonça Filho e Juliano Dornelles, que analisaremos mais adiante.

Em contrapartida, para o ator de teatro, mesmo com todas as instruções, a improvisação de uma cena poderá gerar o risco de ela não ser apreciada. Se o espectador perceber um pseudo movimento no palco isso poderia, por consequência, comprometer o andamento da performance. Apesar dos riscos, a improvisação evidencia o caráter espontâneo do artista. Neste caso, em "teatro a espontaneidade é a mais importante qualidade de um ator" (KUSNET, 1975, p. 98), uma vez que ele adquiriu "a capacidade de conceber sempre com surpresa a ação preestabelecida, como se ela fosse inesperada" (Ibid., p. 99). Assim, os intérpretes podem encenar de modo a encantar a plateia e essa, com isso, é mantida na expectativa para o desfecho da trama.

Com efeito, é evidente a correlação entre o ator de teatro com o de cinema, visto que através da capacidade criativa e espontânea ambos se adaptam ao local de atuação, de modo que a sua representação, ainda que, "interdependente [...] completa, troca, joga, interage" (SANTOS, 2018, p. 5) e, consequentemente, fascina os espectadores.

Em outras palavras: "o cinema não pode esquecer a tremenda experiência de seus períodos iniciais" (EISENSTEIN, 2002, p. 25), isto é, a aprendizagem obtida no teatro, cujo conhecimento pode ser constatado nas atuações de Charles Chaplin. A título de 
exemplo, no longa-metragem Tempos Modernos (1936), o protagonista domina a arte de expressão - neste caso, não em palavras, mas por intermédio da expressão corporal.

Neste contexto, diante do vasto acervo cinematográfico disponível e das diversas possibilidades de ensino-aprendizagem, como aproveitar o recurso de um longa-metragem e explorar a sua potencialidade pedagógica e filosófica? Há alguma estratégia para relacionar um filme com o conteúdo a ser transmitido? Pois, para o ensino de filosofia o não reconhecimento de alguns conceitos filosóficos sobre a dimensão do cinema, bem como algumas estratégias prévias da apresentação de um filme poderia atravancar a já conflituosa relação entre o ensino e a aprendizagem da filosofia. Dado que a justificativa frequente para a reprodução de uma obra na sala de aula é que ela correlaciona-se com a concepção de determinado filósofo, isto é, como se a obra cinematográfica se apropriasse da compreensão filosófica. Outra intenção comum no momento da exibição de um longa-metragem corresponde ao momento estratégico de sensibilização. Uma vez que "costumamos dizer a nossos alunos que, para se apropriar de um problema filosófico, não é suficiente entendê-lo: também é preciso vivê-lo, senti-lo na pele, dramatizá-lo" (CABRERA, 2006, p. 6). Nesse aspecto, destaca-se a conhecida sugestão do professor Silvio Gallo (2012), que recorre ao efeito da sensibilização como um elemento para desenvolver uma sequência metodológica. Nossa intenção, porém, com esta proposta de exibição de um longa-metragem é construir ou repensar o conceito concomitantemente com o texto filosófico, e não apenas utilizar dele pelo seu caráter afetivo, mesmo considerando o valor dessa estratégia metodológica.

Desse modo, para além dessas perspectivas, indicaremos algumas maneiras de pensar o cinema filosoficamente a partir de autores que exploraram esse objeto artístico ao mesmo tempo em que o confrontaram com o saber filosófico.

\section{O cinema que faz pensar}

Inicialmente a análise de um longa-metragem poderia ser explorada através da concepção de "imagem pensante" elaborada pelo filósofo Jacques Rancière (2012). Embora Rancière (2012) fundamente esse conceito através da obra do filósofo Roland Barthes (Cf. BARTHES, 1984), que analisou algumas fotografias com características pensantes, ou seja, que fazem pensar, é razoável refletir sobre o cinema a partir desse entendimento.

A pensatividade da fotografia poderia então ser definida como esse nó entre várias indeterminações. Poderia ser caracterizada como efeito da circulação entre o motivo, o fotógrafo e nós, do intencional e do não intencional, do sabido e do não sabido, do expresso e do não expresso, do presente e do passado. (RANCIÈRE, 2012, p. 110).

Como a fotografia, um objeto estático, faz pensar, eventualmente, o filme como recurso metodológico produza o mesmo efeito, agora por meio de sua sequência e narrativa. Assim, uma "narrativa tem de ter sequência, mas uma sequência não tem necessariamente de ter narrativa" (MENDES, 2013, p. 17). De acordo com essa interpretação, destaca-se, por 
exemplo, do filme - O segredo dos seus olhos (2009), do diretor Juan José Campanella uma cena importante para o desenvolvimento da trama. No momento em que o investigador de um crime bárbaro depara-se com algumas fotografias da vítima em companhia de seus amigos um detalhe lhe desperta interesse: o olhar fixo de um rapaz sobre a jovem assassinada. Seguindo a interpretação de Rancière (2012) a imagem em si não denuncia o criminoso, mas o olhar do protagonista naquele ponto convida o espectador a suspeitar do personagem e questionar os motivos que o levaram a cometer tamanha monstruosidade. No percurso da investigação, o agente descobre que ambos tiveram um relacionamento no passado, o que só reforça a desconfiança. Neste caso, a análise da fotografia, tanto do investigador como do espectador através das lentes da câmera, tem um papel decisivo para o seguimento da narrativa. Em outras palavras, o enquadramento da câmera sobre a fotografia e a continuidade das imagens fazem-nos pensar e criar alternativas para o desfecho da história sem que a mesma tenha nos fornecidos todos os elementos para decifrá-la em sua plenitude. Sendo assim, o espectador é induzido a refletir sobre a imagem e instigado a presumir a respeito do suposto assassino durante as sequências narrativas.

Ainda, em relação à definição de "imagem-pensante", no Prólogo do longa-metragem o Anticristo (2009), do diretor dinamarquês Lars von Trier, pode-se vincular essa conceituação de Jacques Rancière (2012) com as sequências de imagens, sobretudo nos aproximados cinco minutos iniciais do filme em questão. Vale dizer, com a beleza da neve caindo em contraste com o céu nebuloso, o ritmo da câmera - lenta - engendra a impressão de que a rotação normal da terra, por algum instante, teve as suas engrenagens danificadas. Talvez com essa cena o diretor quisesse sinalizar que, do momento da morte de um ente querido até a superação do luto, alguns sujeitos reconstroem o seu estado emocional em um processo vagaroso e conflitante.

Neste cenário, as sequências de imagens reproduzidas lentamente, tanto da parte externa como do ambiente interno da habitação, fornecem alguns elementos para compreendermos o propósito do cineasta, que ora focaliza a câmera sobre o casal protagonizada por Charlotte Gainsbourg e Willem Dafoe - que realiza ato erótico; ora a lente da câmera fixa em uma criança, que se levanta de chofre do berço, pois foi atraída pelo seu ursinho de pelúcia.

Nessa introdução a continuidade das imagens expressa o conceito de Rancière (2012), à medida que a técnica de encadeamento da narrativa provoca questionamentos, tal como: 0 que acontecerá em meio a relação sexual do casal de protagonistas?

Continuando com a observação sobre o desfecho do Prólogo, o menino que caminha a passos trôpegos pelo interior da casa sai de seu dormitório e vai em direção ao de seus pais; em seguida o garoto retorna para o seu quarto, sem ser, ao menos, percebido; deslumbrado pelos flocos de gelo que caem do lado de fora, ele nota a janela entreaberta e debruça-se sobre ela, como se fosse apanhar a neve. Com a tragédia concretizada e com o fim do ato sexual o primeiro ato, assim, encerra-se com dois acontecimentos fundamentais, os quais poderiam, por exemplo, ser repensados sob a perspectiva da Psicanálise freudiana, especialmente 
em relação aos conceitos de "pulsão de vida" e "pulsão de morte", uma vez que a obra cinematográfica avança exibindo as maneiras pelas quais os personagens assimilam ou não a perda do filho de modo terrível e repentino.

Grosso modo, a noção freudiana reside no reconhecimento de que

toda pulsão é uma força inerente ao ser vivo, cuja meta fundamental consistiria em restaurar um estágio anterior de desenvolvimento do organismo que este foi obrigado a abandonar por pressão de circunstâncias exteriores. (GIACÓIA JR, 2012, p. 125).

Por um lado, a "pulsão de vida" é um estimulador de pensamentos e práticas, que ativa o prazer de viver. Portanto mediante a uma "relação entre a energia psíquica da libido e objeto sobre o qual essa energia é investida" (Ibid., p. 131). Por outro lado, a "pulsão de morte" expõe "uma compulsão a repetir vivências de desprazer [...]" (Op. Cit., p. 125), em decorrência de determinado fato, sobretudo traumático, como, por exemplo: martírio; culpa; mutilação etc.

Em Anticristo (2009), esses sentimentos e comportamentos são externados, especialmente, pela personagem que interpreta a mãe da criança que veio a óbito.

É importante ressaltar que tal representação contribui para a construção da imagem da mulher. Neste caso, rotulada como uma pessoa frágil, histérica e neurótica, uma vez que ela não assimila a tragédia. Por conseguinte, reage contra si mesma - martirizando; culpabilizando; mutilando.

Em contrapartida, o homem é representado no longa-metragem como aquele que domina e controla os seus próprios impulsos. Sendo assim, caracterizado como o responsável por conduzir e efetivar a reconstrução do estado emocional de ambos.

De outra maneira, a abordagem de filmes pode ser considerada através do conceito formulado por Gilles Deleuze (1985), cuja conceituação, por sua vez, está fundamentada, principalmente nas obras de Henri Bergson, a saber, Matéria e memória (1990); Evolução criadora (2015).

De acordo com Deleuze, o cinema "oferece imediatamente uma imagem-movimento" (DELEUZE, 1985, p. 11), à medida que promove "a impressão de continuidade" (Ibid., p. 14).

Além disso, "Deleuze nos lembra que Henri Bergson estabeleceu uma estranha relação com o cinema, pois [...] equiparou o funcionamento do aparelho perceptivo humano com a câmera cinematográfica" (LASALVIA, 2018, p. 161). Neste horizonte, o cinema "começa tomado de uma tentativa de reprodução da percepção humana em seu esquema sensório-motor: câmera imóvel, mundo em movimento, plano sequência..." (FARINA; FONSECA, 2015, p. 120).

De maneira semelhante ao esquema funcional primitivo do cinema, 0 cérebro humano capta o mundo em movimento pelos órgãos dos sentidos.

A título de exemplo, a gravação da Saída dos Operários da Fábrica Lumière (1895), através das lentes dos próprios irmãos Lumière ilustra o modo pela qual o objeto de captação dessas primeiras imagens assemelha-se ao aparelho visual humano. 
Segundo Deleuze (1985), o cinema, a princípio, é concebido através da filmagem de um plano fixo. Neste caso, embora a gravação do todo seja limitado, assim como é a nossa percepção do mundo, a imagem permite a sua conceituação na medida em que ela produz uma sequência de imagem/narrativa. Além do mais, a partir do momento que se dominou a técnica da montagem esse processo visual tornou-se mais nítido.

Desse modo, o cinema opera por meio do enquadramento; quadro; plano; decupagem. Através do enquadramento capta-se tudo aquilo que compõe a imagem: "cenários, personagens, acessórios" (DELEUZE, 1985, p. 22). Com esse recurso os componentes expostos são detectados conforme a distribuição de cada plano entre o recorte de contínuos quadros. Neste ponto de vista, o quadro é "informativo e [...] inseparável de duas tendências - à saturação ou à rarefação" (Op. Cit., p. 22), além de conferir outros enfoques à determinada imagem.

No processo em que se tem em determinado quadro um predomínio da saturação, dá-se destaque às cenas principais em detrimento das secundárias. Sendo assim, as principais podem, contudo, ocupar o fundo da imagem no instante do enquadramento, de tal modo que o resultado perceptível sob determinada imagem é de quase total homogeneidade entre a ênfase dada nas imagens primária e na secundária. Já, no processo de rarefação, o foco da câmera se dá sobre um único objeto. Seu grau máximo de destaque, por sua vez, pode produzir uma tela "inteiramente negra ou branca" (Ibid., p. 23).

A propósito desses efeitos, pode-se verificar, por exemplo, no início do longa-metragem Parasita (2019), essa técnica de rarefação no cinema, isto é, o enquadramento que exibe a aplicação de um produto - fumacê - capaz de eliminar mosquitos, insetos, etc. Desta forma, em meio à nuvem de fumaça, a família que observa do interior da casa à aplicação do produto químico desaparece quase que por completo, realçando, assim, a tela branca.

Nesta perspectiva, "o quadro nos ensina [...] que a imagem não se dá apenas a ver" (Op. Cit., p. 23). Mas ela estimula pensamentos e reflexões. Em tal caso, o filme sul-coreano trata de famílias que vivem em porões sujos e apertados em contraste com outras que residem em casas suntuosas. A partir disso, obra cinematográfica expõe o grave problema da desigualdade social.

$\mathrm{Na}$ narrativa, a estratégia adotada pelo governo de lançar o fumacê em áreas de circunstâncias precárias, simboliza - ao menos na obra cinematográfica - uma tentativa de controlar pragas indesejadas, sejam estas reais ou metafóricas. Neste caso específico do filme, poderíamos pensar que os próprios habitantes, que vivem em condições desumanas, são identificados como uma epidemia a seu modo, e, por isso, devem ser erradicados.

Ainda a respeito do processo de rarefação como técnica do cinema, pode-se constatar, por exemplo, o uso do mecanismo de escurecimento da tela no longa-metragem 1917 (2019), que foi ambientado no contexto da primeira guerra mundial e narra as aventuras de dois soldados (George Mackay; Dean-Charles Chapman), os quais têm por missão evitar o massacre de 1.600 militares, uma vez que determinados comandantes julgavam estar encurralando as forças inimigas enquanto na verdade, estavam lançando os seus próprios soldados para uma armadilha. 
Em meio a uma série de peripécias, há uma cena específica que sintetiza o efeito da rarefação no cinema. Nesta circunstância, quando o soldado responsável de enviar a mensagem ao seu superior adentra uma cidade bombardeada, ele troca tiros com um oponente. De chofre, o mensageiro é alvejado por um disparo. Neste instante do longametragem, uma imagem negra cobre a tela por aproximadamente dezesseis segundos. Ademais, um silêncio fúnebre acompanha a sequência, pois a ausência de outros elementos na imagem representa o período em que o soldado ficou desacordado, devido ao forte impacto do projétil em seu corpo.

Prosseguindo com as análises de Deleuze (1985, p. 31), outros aspectos que exercem uma importância fundamental na produção de um filme são as técnicas da decupagem e do plano, uma vez que a "decupagem é a determinação do plano, e o plano a determinação do movimento". E, esse, por sua vez, responsável por alterar o todo que é constituído entre as partes, quer dizer, a conexão entre os cortes efetuados por cada plano reconstituí o todo. Com efeito, "o plano encontra sua determinação concreta na medida que está sempre garantindo passagem de um aspecto ao outro” (Ibid., p. 32).

Neste horizonte, o plano é a própria "imagem-movimento. Enquanto reporta o movimento a um todo que muda, é o corte móvel de uma duração" (lbid., p. 35).

Para ilustrar essa concepção de imagem-movimento, o próprio Deleuze faz referência ao longa-metragem Frenesi (1972) do cineasta Hitchcock.

Por exemplo: a câmera segue um homem e uma mulher que
sobem uma escada e chegam a uma porta, que o homem abre; em
seguida a câmera os deixa e retrocede num único plano, contorna
a parede exterior do apartamento, atinge a escada descendo-a
de costas, desemboca na calçada e se ergue pelo exterior até a
janela opaca do apartamento visto de fora. Tal movimento, que
modifica a posição relativa de conjuntos imóveis, só é necessário
se exprime algo que está acontecendo, uma mudança num todo
que passa, ele mesmo, por estas modificações: a mulher está
sendo assassinada, ela entrara livre e não pode mais esperar
socorro algum, o assassinato é inexorável. (Op. Cit., 1985, p. 31)

Assim, considerando que para Deleuze e Guattari (1993, p. 29) "cada conceito opera um novo corte, assume novos contornos, deve ser reativado ou recortado". Um filme, nessa dinâmica, opera tendo em vista esses elementos. Por isso, filme e filósofo produzem conceitos a partir de componentes que permitem acompanhar acontecimentos das coisas e dos seres (Cf. Ibid., p 45). De tal maneira que ambos através de um plano de imanência criam ideias, as quais transitam de um ponto de vista a outro, sobretudo reconstituindo-se no devir (Cf. Ibid., p. 51). Nesta perspectiva, o "conceito - seu plano de imanência - é desenvolvida uma zona de vizinhança necessária com outros conceitos, estabelecendo uma relação de composição em rede: é o devir do conceito" (VASCONCELLOS, 2005, p. 1223). Em suma: o conceito é "a ferramenta do filosofar, o instrumento da filosofia" (Ibid., p. 1224). Com base nessas afirmações, pode-se concluir que ambos fenômenos 
culturais - filosofia e filme - estimulam os sujeitos a pensarem e a saírem de determinada condição de imobilidade, dado que eles explicitam problemas e "inventam" conceitos.

Neste contexto, semelhante a Deleuze (1985), Julio Cabrera (2006) observa o cinema filosoficamente. Com isso ele engendra a concepção de conceitos-imagem (Cf. CABRERA, 2006, p. 9). Quer dizer, é imprescindível partir dos elementos lógicos do filme para compreendê-lo em sua plenitude. De acordo com este ponto de vista, o espectador é afetado pela lógica (Cf. Ibid., p. 11) interna da obra cinematográfica, uma vez que ela estimula sobretudo a pensar e não simplesmente a se emocionar. Assim, para que o conceito-imagem seja observado é fundamental a prévia das sequências de imagens. Desta maneira, a imagem ou a cena em si não representam a concepção de conceitos-imagem. Antes ela é representada através da continuidade da narrativa, ou seja, a fundamentação conceitual passa a ter sentido à medida que as cenas iniciais, intermediárias e finais são consideradas dentro do mesmo contexto (Cf. Ibid., p. 12). De acordo com esta formulação do conceito-imagem, é possível realizar uma leitura filosófica de um filme. Contanto que ele seja tratado "[...] como um objeto conceitual, como um conceito visual e em movimento" (Ibid., p. 30). Uma vez que existe similaridade entre o filme e o texto filosófico, pois ambos para conceituar desenvolvem um método introdutório que permite ao pensamento presumir as cenas posteriores. Esse gesto nem sempre permite compreender o desfecho da obra (filme ou texto) de forma antecipada. Ele, porém, é o resultante do modo provocativo da condição singular de dado diretor cinematográfico e da peculiaridade de um filósofo.

Por esse ângulo, o filósofo para expor um conceito estrutura as várias cenas, as quais exigem do seu leitor habilidade de abstração para assimilar a totalidade do pensamento. Platão (Cf. 1970), por exemplo, sugere no célebre "mito da caverna" - que o sujeito cuja existência está alheia ao conhecimento, vive com um entendimento enigmático da realidade, tal como o dos indivíduos que foram coagidos a permanecer no interior da caverna, na penumbra, sem jamais ter testemunhado a realidade exterior. Cenário a partir do qual Platão (1970) desenvolve o conceito do homem capaz de se livrar dos grilhões e com isso contemplar o que há no mundo exterior. Além do mais, esse sujeito poderia auxiliar os cativos para que estes também testemunhem a aparência real das coisas. Antes, porém, é estimulada no leitor de Platão (1970) a idealização sobre as "coisas" como forma preparativa do conceito. Dessa forma, Platão (1970) propõe sobretudo a superação do mundo sensível, da aparência, da cópia, das inverdades; defende a contemplação do mundo supra-sensível, da realidade, da originalidade, da verdade. Em outras palavras: "para compreender o mundo, precisamos sair do plano sensível dos meros particulares diversos e mutáveis e investigar suas ideias correspondentes, suas naturezas lógicas” (CABRERA, 2006, p. 35).

De modo semelhante, o filósofo Friedrich Nietzsche (Cf. 2011) que anunciara o conceito do "além do homem", através do personagem Zaratustra, também utiliza o recurso de preparação do conceito. Neste caso, o próprio protagonista participa da construção do conceito, pois ele está em processo de transmutação, isto é, antes de proclamar o Übermensch (a superação do homem pelo próprio homem) o protagonista necessita de preparação para 
que suporte o peso da decisão e das consequências futuras de sua proclamação. Em seu caso específico, Zaratustra se refugia no alto da montanha e sua construção conceitual se estende por dez anos. Solitário de humanos convive com a natureza donde engendra sua inspiração. O conceito que Zaratustra anunciara é tão pesado que a gravidade o move para baixo, pois é entre os homens, embaixo da montanha, que a experiência do pensamento deve fazer sentido. Assim, é na travessia da montanha, no povoado, no contato com os outros personagens que Nietzsche constrói o conceito por intermédio de Zaratustra.

Com referência à construção do conceito através da cinematografia, pode-se encontrar, por exemplo, no longa-metragem Os oito odiados (2015), do diretor Quentin Tarantino, uma produção conceitual sobre a ideia de justiça. Na cena, estão presentes o personagem do carrasco (interpretado por Tim Roth), que é encarregado de executar a pena de morte; o caçador de recompensa (Kurt Russell); e a prisioneira entregue por ele (Jennifer Jason Leigh) para que seja castigada em razão das contravenções cometidas.

De acordo com o algoz, a sociedade civilizada considera justo o enforcamento do malfeitor, desde que tenha provas satisfatórias e a punição seja aplicada pelo próprio Estado, mas, se os familiares da vítima executarem o suplício do modo que bem entenderem, como forma de retaliação, tal gesto não se qualificaria por justiça. Nesse sentindo, questiona o executor: qual a diferença entre essas atitudes? Dado que para o carrasco não há prazer naquilo que faz, pois se tornou um hábito. Logo, o homem que move a alavanca da forca, o qual representa a justiça, é sem paixão, uma vez que quando a justiça se submete a esse sentimento é temerário que tal gesto não seja justo.

Outrossim, a noção de conceitos-imagem pode ser apreciada conforme se apresenta no filme Bacurau (2019). Dentre as diversas cenas (imagens) que constroem o enredo do longa-metragem, algumas nos fazem pensar. O filme brasileiro narra a história de um povoado, que, em meio às ameaças estrangeiras e locais, resiste à toda forma de dominação. Desse longa-metragem destacamos alguns episódios. Inicialmente a tática dos personagens (Udo Kier; Karine Teles; Antonio Saboia), que representam os forasteiros, os quais tinham por tarefa exterminar os habitantes da longínqua cidade. O método adotado para legitimar as suas ações consistiu em excluir, literalmente, do mapa a localização da cidade, bem como os próprios moradores. Assim, apagados seus vestígios, os habitantes de Bacurau são identificados como seres apátridas, indivíduos que não tem direito à água, à vida. Por essa razão, os seus extermínios não são contabilizados, uma vez que esses sujeitos não são mais considerados cidadãos por possuírem modos de existência diferentes dos colonizadores.

Outra cena que desperta bastante atenção, logo no início do filme, é o momento em que ocorre um velório. Quando a personagem de Bárbara Colen pela lente da câmara fixa o olhar sob o caixão, ele imediatamente começa a jorrar água. Desse fato, as questões que podem ser colocadas são: os outros personagens também estariam tendo a mesma visão? Aliás, estaria a personagem sob o efeito de um poderoso psicotrópico? De qualquer maneira, substâncias psicotrópicas são em Bacurau apropriadas para estimular resistências contra o opressor, sendo justificadas em um momento posterior da obra. 
Além disso, a partir do filme Bacurau, pode-se problematizar acerca da legitimidade do uso da Gewalt - violência e poder -, conforme interpretado por Walter Benjamin (1986).

$\mathrm{Na}$ visão dos forasteiros o povo nativo agiu, ao se defender, com extrema violência, o que nos faz questionar. O líder dos colonizadores (Udo Kier), no momento em que está prestes à ser soterrado, questiona sobre o porquê de tanta violência. Com isso, expõe e fragiliza a seguinte interrogação filosófica: há alguma violência legítima?

Por um lado, os conquistadores se apropriaram do recurso da violência para legitimar o extermínio de pessoas que possuem modos de existência, que não condiziam com a dos indivíduos assim ditos civilizados. Aliás, estabeleceram um mecanismo de pontuação, quando uma vida era ceifada. Portanto, o ato de matar tornou-se um jogo.

Por outro lado, os supostos bárbaros apoderaram-se do mecanismo da violência para validar a defesa de seus costumes; de suas terras; em suma: de suas vidas.

Nesse sentido, Walter Benjamin (1986) tratou a respeito da legitimidade da violência, conflitando a concepção de direito natural com o direito positivo.

Desse modo, considerou que o "direito natural visa, pela justiça dos fins, 'legitimar' os meios, o direito positivo visa 'garantir' a justiça dos fins pela legitimidade dos meios" (BENJAMIN, 1986, p. 161).

Em síntese, o direito natural legitima o meio, após identificar um fim justo; enquanto que o direito positivo assegura a justiça do fim, pela legitimidade do meio, isto é, só reage se os meios forem legítimos, ao passo que considera determinado fim justo. Contudo, nenhum entendimento interroga o que é justiça? Em todo caso, poderia se problematizar, em qual forma de direito se enquadrariam os personagens do longa-metragem Bacurau? A propósito, perante esse antagonismo presente no filme, bem como na interpretação filosófica, haveria espaço na política contemporânea para a prática da legitimidade da violência, independentemente da gravidade do fato que se busca responder?

Diante dessas problematizações, espera-se que sejam exploradas através do longametragem as dimensões filosóficas presentes também nesses recursos. Assim, seja por meio do conceito de "imagem-pensante", seja mediante a concepção de "imagem-movimento" ou por intermédio da compreensão de "conceitos-imagem" é factível filosofar através de filmes.

\section{Considerações finais}

No artigo, esperamos ter evidenciado e consequentemente demonstrado, de que é possível filosofar através de filmes, uma vez que esse instrumento didático estimula reflexões filosóficas. Nesta Perspectiva, a partir da reflexão sobre o filme $O$ segredo dos seus olhos (2009), bem como acerca do longa-metragem Os oito odiados (2015), por exemplo, é viável explorar o recurso cinematográfico de modo filosófico, pois os elementos que aparecem nessas obras são aqueles investigados pelo filósofo alemão Friedrich Nietzsche, sobretudo na obra Genealogia da moral (1998), a saber, do ressentimento, da vingança e da justiça. Nesta perspectiva, Nietzsche (1998), compreende, de certa forma, que a justiça 
está relacionada a um certo sentimento de fraqueza, a saber, o do ressentimento. Desse modo, o sujeito debilitado por esse estado psicológico tende a encontrar um culpado pelo seu respectivo enfraquecimento. Localizando o responsável fixa-se uma meta: compensar um dano sofrido com outra atitude como sinal de equiparação. Por sua vez, Nietzsche (1998) critica o entendimento do professor berliniense Eugen Dühring que concebeu a origem da justiça sob a perspectiva da vingança, ou seja, de um ato reativo. De modo que a meta capaz de equilibrar o prejuízo indesejado configura-se no ato da vingança. Por um lado, dissimulada de uma ação justa; por outro, originada na condição de ressentimento.

Neste horizonte, o diálogo ressaltado anteriormente da obra de Tarantino, a respeito da legitimidade e do cumprimento da justiça, mediante certa punição executada pelo Estado, corrobora com a caracterização filosófica do cinema, uma vez que em Nietzsche (1998) encontra-se a seguinte definição:

pôr fim, entre os mais fracos a ele subordinados (grupos ou indivíduos), ao insensato influxo do ressentimento, seria retirado das mãos da vingança a luta contra os inimigos da paz e da ordem, seja imaginando, sugerindo ou mesmo forçando compromissos, seja elevando certos equivalentes de prejuízos à categoria de norma, à qual de uma vez por todas passa a ser dirigido o ressentimento. (NIETZSCHE, 1998, 64).

Além disso, esse ponto da filosofia nietzschiana poderia ser considerada também na obra cinematográfica Parasita (2019), principalmente no que diz respeito às transformações sentimentais que vivenciam os personagens que se encontram na condição de pobreza. Como as suas estruturas emocionais foram estimuladas por suas respectivas paixões (Cf.

LEAL, 2020), de certa maneira, quase todas elas se originaram do estado comportamental mais resistente, a saber, o do ressentimento. A lógica desse sentimento torpe opera a partir da seguinte dinâmica: da cobiça surge a inveja; da raiva o rancor; do ódio a vingança. Todos esses, por sua vez, presentes nos intérpretes, que se encontram na situação de miséria. Assim sendo, esperamos ter produzido uma integração entre a filosofia e a obra cinematográfica para incentivar pensamentos filosóficos e consequentemente atitudes reflexivas, críticas e problematizadoras.

\section{Referências}

ADORNO, Theodor; HORKHEIMER, Max. Dialética do esclarecimento: fragmentos filosóficos. Trad. Guido Antonio de Almeida. Rio de Janeiro: Jorge Zahar, 1985.

BARTHES, Roland. A câmara clara: nota sobre a fotografia. Trad. Júlio Castañon Guimarães. Rio de Janeiro: Nova Fronteira, 1984.

BENJAMIN, Walter. A obra de arte na era de sua reprodutibilidade técnica. In: Magia e técnica, arte e política. Trad. Sergio Paulo Rouanet. 3. Ed. São Paulo: Brasiliense, 1987.

BENJAMIN, Walter. Crítica da Violência. Crítica do Poder. In: Documentos de Cultura, Documentos de Barbárie. Trad. e Org. de Willi Bolle. São Paulo: Cultrix. EDUSP, 1986. 
BERGSON, Henri. Matéria e Memória. Ensaio sobre a relação do corpo com o espírito. São Paulo, Ed. Martins Fontes, 1999.

BERGSON, Henri. Evolução Criadora. São Paulo, Folha de São Paulo, 2015.

CABRERA, Julio. O cinema pensa: uma introdução à filosofia através dos filmes. Rio de Janeiro: Rocco, 2006.

DELEUZE, Gilles. A Imagem-movimento, cinema 1. Trad. Stella Senra. São Paulo: Brasiliense, 1985.

DELEUZE, Gilles; GUATTARI, Félix. O que é a filosofia? Trad. Bento Prado Jr. e Alberto Alonso Munoz. 2. Ed. São Paulo: 34, 1993.

EISENSTEIN, Sergei. A forma do filme. Trad. Tereza Ottoni. Rio de Janeiro: Jorge Zahar Ed., 2002.

FARINA, Juliane Tagliari; FONSECA, Tania Mara Galli Fonseca. "O cine-pensamento de Deleuze: contribuições a uma concepção estético-política da subjetividade". Psicologia USP, São Paulo, v. 26, n. 1, jan./abr. 2015.

FREITAS, Alexander de; COUTINHO, Karyne Dias. "Cinema e educação: o que pode o cinema?” Educação e filosofia, Uberlândia, v. 27, n. 54, jul./dez. 2013.

GALLO, Silvio. Metodologia do ensino de filosofia: uma didática para o ensino médio. Campinas: Papirus, 2012.

GIACOIA JUNIOR, Oswaldo. "Ontologia e metapsicologia: considerações sobre o dualismo pulsional”. Ideias, Campinas, n. 4, 2012.

KUSNET, Eugênio. Ator e método. Rio de Janeiro: Serviço Nacional de Teatro, 1975.

LA SALVIA. André Luis. A questão da criação de imagens no cinema para Gilles

Deleuze. In: ARAUJO, Denise; BARROS, Ana Taís M. P.; CONTRERA, Malena; ROCHA, Rose de Melo (Org.). Imag(em)inário, imagens e imaginário na comunicação. 1. Ed. Rio Grande do Sul: Editora Imaginalis / Página 42, 2018.

LEAL, Hermes. A estrutura invisível do roteiro de "Parasita". Revista de cinema, 2020. Disponível em:http://revistadecinema.com.br/2020/02/a-estrutura-invisível-do-roteiro-deparasita/. Acesso em: 23 de fev. de 2020.

MENDES, João Maria. O filme que filosofa. Lisboa: Biblioteca da ESTC, 2013.

NIETZSCHE, Friedrich Wilhelm. Assim falou Zaratustra. Trad. Paulo César de Souza. São Paulo: Companhia das Letras, 2011.

NIETZSCHE, Friedrich Wilhelm. Genealogia da moral: uma polêmica. Trad. Paulo César de Souza. São Paulo: Companhia das Letras, 1998.

PLATÃO. A República. Trad. Eduardo Menezes. São Paulo: HEMUS, 1970.

RANCIĖRE, Jacques. O espectador emancipado. Trad. Ivone C. Benedetti. São Paulo: Martins Fontes, 2012.

SANTOS, Marcelo Moreira. O ator no cinema: uma abordagem sistêmica sobre seu processo de criação. Biblioteca on-line de ciências da comunicação, 2018. Disponível em: bocc.ubi.pt/pag/santos-marcelo-2018-ator-cinema.pdf. Acesso em: 06 de fev. de 2020. 
VASCONCELLOS, Jorge. A filosofia e seus intercessores: Deleuze e a não-filosofia.

Educação e sociedade, Campinas, v. 23, n. 93, set./dez. 2005.

\section{Referências filmográficas}

ANTICRISTO. [Antichrist]. Direção e Roteiro: Lars von Trier. França: Meta Louise Foldager, 2009. (109 min.).

BACURAU. Direção: Kleber Mendonça Filho e Juliano Dornelles. Produção: Emilie Lesclaux, Saïd Ben Saïd e Michel Merkt. Roteiro: Kleber Mendonça Filho e Juliano Dornelles. Brasil/França: SBS Productions et al., 2019. (132. min.).

DEUS e o Diabo na Terra do Sol. Direção: Glauber Rocha. Produção: Jarbas Barbosa, Luiz Augusto Mendes, Glauber Rocha e Luiz Paulino dos Santos. Roteiro: Glauber Rocha e Walter Lima Jr. Brasil: Copacabana Filmes, 1964. (120 min.).

FRENESI. [Frensy]. Direção e Produção: Alfred Hitchcock. Roteiro: Anthony Shaffer. Estados Unidos: Universal Pictures, 1972. (116. min.).

1917. [1917]. Direção: Sam Mendes. Produção: Sam Mendes, Pippa Harris, Jayne-Ann Tenggren, Callum McDougall e Brian Oliver. Roteiro: Sam Mendes e Krysty Wilson-Cairns. Reino Unido/Estados Unidos: DreamWorks Pictures et al., 2019. (119 min.).

O SEGREDO dos Seus Olhos [EI Secreto de Sus Ojos]. Direção: Juan José Campanella. Produção: Mariela Besuievski, Juan José Campanella e Carolina Urbieta. Roteiro: Eduardo Sacheri e Juan José Campanella. Argentina: Tornaso, Films, Haddock Films e 100 Bare, 2009. (127 min.).

OS OITO odiados. [The Hateful Eight]. Direção: Quentin Tarantino. Produção: Richard N. Gladstein, Shannon Mclntosh e Stacey Sher. Roteiro: Quentin Tarantino. Estados Unidos: The Weinstein Company, 2015. (167 min.).

PARASITA. [Gisaengchung]. Direção: Bong Joon-ho. Produção: Kwak Sin-ae, Moon Yangkwon e Jang Young-hwan. Roteiro: Bong Joon-ho; Han Jin-won. Coreia do Sul: Barunson E\&A Corp, 2019. (132 min.).

SAÍDA dos Operários da Fábrica Lumière. [La Sortie de l'usine Lumière à Lyon]. Direção: Louis Lumière. França: 1895. (48 seg.).

TEMPOS Modernos. [Modern Times]. Direção e Roteiro: Charles Chaplin. Estados Unidos: MK2, 1936. (87 min.).

\section{Correspondência}

Marcos Machado - Rua Riachuelo, 222, Ap. 503, Centro, CEP: 80020-250, Curitiba, Paraná, Brasil.

\section{(c) $)(1)(9)$}

This work is licensed under a Creative Commons Attribution-NonCommercial 4.0 International (CC BY-NC 4.0) 